Check for updates

Cite this: RSC Adv., 2020, 10, 25358

Received 4th May 2020

Accepted 28th June 2020

DOI: $10.1039 /$ d0ra04008h

rsc.li/rsc-advances

\title{
Synthesis of polyhydroquinolines and propargylamines through one-pot multicomponent reactions using an acidic ionic liquid immobilized onto magnetic $\mathrm{Fe}_{3} \mathrm{O}_{4}$ as an efficient heterogeneous catalyst under solvent-free sonication $\dagger$
}

\begin{abstract}
Hai Truong Nguyen, (D) ab Vy Anh Truong (D) ab and Phuong Hoang Tran (D) *ab
A nano-sized $\mathrm{Fe}_{3} \mathrm{O}_{4}$-supported Lewis acid ionic liquid catalyst for the synthesis of polyhydroquinolines and propargylamines under ultrasound irradiation has been developed. LAIL@MNP was synthesized from imidazolium chlorozincate(॥) ionic liquid grafted onto the surface of $\mathrm{Fe}_{3} \mathrm{O}_{4}$ nanoparticles and evaluated by FT-IR, TGA, SEM, Raman, TEM, ICP-OES, and EDS. The multicomponent synthesis of polyhydroquinolines and propargylamines proceeded smoothly to afford the desired products in high yields. LAIL@MNP can be separated easily from the reaction mixture and reused for several runs without a significant degradation in catalytic activity.
\end{abstract}

\section{Introduction}

The application of heterogeneous catalysts in organic synthesis has attracted much attention due to the prominent features of these catalysts, such as high efficiency, simple recovery, and reusability. ${ }^{1}$ However, the major limitation of heterogeneous catalysts is their low catalytic activity and selectivity because of slow dispersibility in the solvent. ${ }^{2}$ Magnetic nanoparticles (MNPs) are known as a new type of catalyst support because of their easy synthesis, good stability, high surface area, and facile separation from the reaction mixture. ${ }^{3}$ Currently, there are many reports about the catalytic performance of $\mathrm{Fe}_{3} \mathrm{O}_{4} @ \mathrm{ZrO}_{2} /$ $\mathrm{SO}_{4}{ }^{2-} \mathrm{MNPs},{ }^{4} \quad \mathrm{Fe}_{3} \mathrm{O}_{4} @ \mathrm{SiO}_{2}-\mathrm{SO}_{3} \mathrm{H} \quad \mathrm{MNPs}^{5,6} \quad \mathrm{CoFe}_{2} \mathrm{O}_{4} @ \mathrm{SiO}_{2}-$ $\mathrm{SO}_{3} \mathrm{H}$ MNPs, ${ }^{7} \mathrm{Fe}_{3} \mathrm{O}_{4} @ \mathrm{ZrO}_{2}-\mathrm{Pr}-\mathrm{SO}_{3} \mathrm{H}$ MNPs, ${ }^{8}$ and $\mathrm{CuFe}_{2} \mathrm{O}_{4}$ (a) $\mathrm{SO}_{3} \mathrm{H} \mathrm{MNPs}^{9}$ in organic synthesis. Recently, Lewis acidic ionic liquids supported on magnetic nanoparticles have been extensively studied in organic synthesis due to high efficiency, simple recovery by an external magnet, excellent thermal stability, and reuse without loss of the activity. ${ }^{\mathbf{1 0 - 1 4}}$

Polyhydroquinoline heterocycles (PHQ) have received considerable interest owing to their pharmacological activities such as anticancer, ${ }^{15}$ antiplasmodial, ${ }^{16}$ antiatherosclerotic, ${ }^{17}$ antibacterial, $^{\mathbf{1 8}}$ antiproliferative, ${ }^{\mathbf{1 9}}$ antimalarial, ${ }^{\mathbf{2 0}}$ calcium

${ }^{a}$ Department of Organic Chemistry, Faculty of Chemistry, University of Science, Ho Chi Minh City, 721337, Vietnam.E-mail: thphuong@hcmus.edu.vn ${ }^{b}$ Vietnam National University, Ho Chi Minh City, 721337, Vietnam

$\dagger$ Electronic supplementary information (ESI) available. See DOI: 10.1039/d0ra04008h antagonists, ${ }^{21}$ and antidiabetic properties ${ }^{22}$ (Scheme 1). Various methods have been developed to synthesize polyhydroquinolines, ${ }^{23-25}$ pyridines, ${ }^{26}$ pyridylalanines,${ }^{27}$ pyrroles,${ }^{28}$ furans,${ }^{28}$ etc. via the multicomponent Hantzsch reaction. Recently, different catalysts for the synthesis of PHQ from aldehydes, $\beta$-dicarbonyl compounds, active methylene compounds, and ammonium acetate have been reported including metal triflates, ${ }^{29}$ zeolites, ${ }^{30}$ ionic liquids, ${ }^{31-33}$ nanoparticles, ${ }^{34-40}$ heterogeneous nanocatalyst, ${ }^{41,42}$ metal halide, ${ }^{43-45}$ organic solid acid, ${ }^{46}$ enantioselective organocatalysis, ${ }^{47}$ nanocomposites,${ }^{48}$ Brönsted acidic. ${ }^{49}$

Propargylamine derivatives are widely used in the pharmaceutical industry (Scheme 2), ${ }^{50}$ which are known as precursors in the formation of quinolines, ${ }^{51}$ oxazoles, ${ }^{52}$ imidazoles, ${ }^{53}$ indolizines, ${ }^{54}$ oxazolidinones, ${ }^{55}$ aza-anthraquinone, ${ }^{56}$ phenanthrolines, ${ }^{57}$ pyrroles $^{58}{ }^{5 y}$ pyrolidines, ${ }^{59}$ dihydropyridine, ${ }^{60}$ and pyridocoumarins. ${ }^{61}$ Moreover, some propargylamine derivatives had been committed as energetic anti-apoptotic agents ${ }^{62}$ and useful in treating Parkinson's disease patients. ${ }^{63}$ There were<smiles>CCOC(=O)C1=C(C)NC2=C(C(=O)CC(C)(C)C2)C1c1ccc(-c2ccccc2)cc1</smiles>

Scheme 1 Some bioactive polyhydroquinolines. 
<smiles>C#CCN(C)C(C)Cc1ccccc1</smiles><smiles>C#CCNC1CCc2ccccc21</smiles><smiles>C#CNC1Cc2cc(Oc3ccccc3)ccc2N1</smiles>

Selegilin

Rasagilin<smiles>C#CCNC1CCc2ccc(OC(=O)N(C)CC)cc21</smiles>

Ladostigil

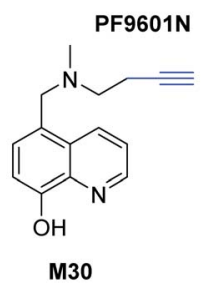

Scheme 2 Some bioactive propargylamines.

several classical methods for the preparation of propargylamines, and the straightforward and efficient method was $\mathrm{A}^{3}$ coupling from alkynes, aldehydes, and amines. ${ }^{64}$

As a continuation of previous work involving the application of Lewis acidic ionic liquids supported onto magnetic nanoparticles in organic synthesis, ${ }^{65}$ we report herein the use of the material as a recyclable catalyst for multicomponent reactions in the synthesis of polyhydroquinolines through Hantzsch condensation and propargylamines through $\mathrm{A}^{3}$-coupling reaction under solvent-free sonication.

\section{Results and discussion}

\section{Synthesis of LAIL@MNP}

The LAIL@MNP was synthesized following a previously reported procedure ${ }^{65}$ The magnetic nanoparticle supported ionic liquid catalyst was prepared in a few steps. MNPs were obtained by a simple co-precipitation method in the presence of $\mathrm{KOH}$ solution. Next, the imidazole chloride ionic liquid was synthesized from 3-chloroethoxypropylsilane and imidazole. Then, imidazole-functionalized magnetic $\mathrm{Fe}_{3} \mathrm{O}_{4}$ nanoparticle (IL@MNP) was reacted with $\mathrm{ZnCl}_{2}$ to afford the LAIL@MNP. Characterization of the synthesized nano- $\mathrm{Fe}_{3} \mathrm{O}_{4}$ and LAIL@MNP was determined using Fourier transform infrared (FT-IR) spectroscopy, scanning electron microscopy (SEM), transmission electron microscopy (TEM), thermo-gravimetric analysis (TGA), energy dispersive spectrum (EDS), and Raman

spectrum (ESI, Fig. S1-S4†). The amount of zinc element in LAIL@MNP was found to be $0.3 \mathrm{mmol} \mathrm{g}^{-1}$ by ICP-MS.

\section{Synthesis of polyhydroquinolines}

The multicomponent reaction is one of the attractive tools in the synthesis of bioactive compounds. ${ }^{66,67}$ The catalytic activity of LAIL@MNP-catalyzed was performed the synthesis of polyhydroquinolines via Hantzsch reaction, four-component condensation reactions of dimedone, ethyl acetoacetate, ammonium acetate and aldehydes under solvent-free sonication. As shown from Table S1 (please see in ESI $\dagger$ ), the condensation reaction between benzaldehyde, dimedone, ethyl acetoacetate, and ammonium acetate in the presence of LAIL@NMP $(15 \mathrm{mg})$ provided in 68\% yield under sonication at room temperature for $60 \mathrm{~min}$ (Table S1, $\uparrow$ entry 5). Interestingly, the excellent yield was observed when the reaction $80^{\circ} \mathrm{C}$ within 45 min (Table S1, $\uparrow$ entry 9). Then, the loading of LAIL@NMP was examined in various weights ranging from $1 \mathrm{mg}$ to $20 \mathrm{mg}$, and the best yield was attained with $15 \mathrm{mg}$ of LAIL@NMP. Table 1 shows that LAIL@MNP is also a suitable catalyst for the synthesis of polyhydroquinolines.

LAIL@NMP catalyzed the Hanzsch condensation of aldehyde (1.0 $\mathrm{mmol})$, dimedone $(1.0 \mathrm{mmol})$, ethyl acetoacetate $(1.0$ $\mathrm{mmol})$, and ammonium acetate $(2.0 \mathrm{mmol})$ solvent-free sonication. As shown in Table 2, the reaction was proceeded smoothly with cyclohexanecarbaldehyde to provide the product in $88 \%$ yield was for 45 min under sonication. Ortho- or parasubstituted benzaldehydes containing electron-poor groups such as chloro and fluoro exhibited weaker activity than benzaldehyde. For those bearing electron-rich groups such as methyl, methoxy, and tert-butyl at the para position, the yields were nearly equal to that of benzaldehyde. Substrates containing $o$-substituted polar functional groups, such as $-\mathrm{OH}$ and $-\mathrm{COOH}$, afforded the respective products whose yields were $20 \%$ less than that of benzaldehyde. The method was also efficient for furan aldehydes to give the desired products in $79-89 \%$ yields.

A plausible mechanism for the synthesis of polyhydroquinolines using LAIL@NMP was demonstrated in Scheme 3. The zinc species of LAIL@MNP catalyst coordinated with oxygen on the carbonyl group of benzaldehyde which

Table 1 Comparative effectiveness for the four-component synthesis of polyhydroquinolines

\begin{tabular}{|c|c|c|c|c|}
\hline Entry & Catalyst & $\begin{array}{l}\text { Temperature } \\
\left({ }^{\circ} \mathrm{C}\right)\end{array}$ & Time (h) & Yield (\%) \\
\hline 1 & $\mathrm{Yb}(\mathrm{OTf})_{3} / \mathrm{EtOH}(5 \mathrm{~mol} \%)$ & r.t. & 5 & 90 (ref. 29) \\
\hline 2 & $p$-TSA/EtOH (10 mol\%) & r.t. & 2 & 93 (ref. 68) \\
\hline 3 & Scolecite/EtOH (200 mg) & reflux & 0.75 & 93 (ref. 69) \\
\hline 4 & $\mathrm{Hf}\left(\mathrm{NPf}_{2}\right)_{4} / \mathrm{C}_{10} \mathrm{H}_{18}(1 \mathrm{~mol} \%)$ & 60 & 3 & 95 (ref. 24) \\
\hline 5 & SSA/solvent-free $(0.20 \mathrm{mmol}, 0.08 \mathrm{~g})$ & 60 & 0.75 & 92 (ref. 70) \\
\hline 6 & $\mathrm{Sc}(\mathrm{OTf})_{3} / \mathrm{EtOH}(5 \mathrm{~mol} \%, 25 \mathrm{mg})$ & r.t. & 4 & 93 (ref. 23) \\
\hline 7 & DBH/solvent-free (10 mol\%) & 130 & 0.5 & 90 (ref. 71) \\
\hline 8 & Nano Pd-(0)/THF (2 step) & reflux & 4.3 & 87 (ref. 35) \\
\hline 9 & $\mathrm{Cs}_{2.5} \mathrm{H}_{0.5} \mathrm{PW}_{12} \mathrm{O}_{40} /$ melting metal $(0.01 \mathrm{mmol})$ & 110 & 0.1 & 92 (ref. 72) \\
\hline 10 & Present work: LAIL@MNP (15 mg), solvent-free & 80 & 0.75 & 97 \\
\hline
\end{tabular}


Table 2 The synthesis of various polyhydroquinolines using LAIL@MNP under solvent-free sonication ${ }^{a}$
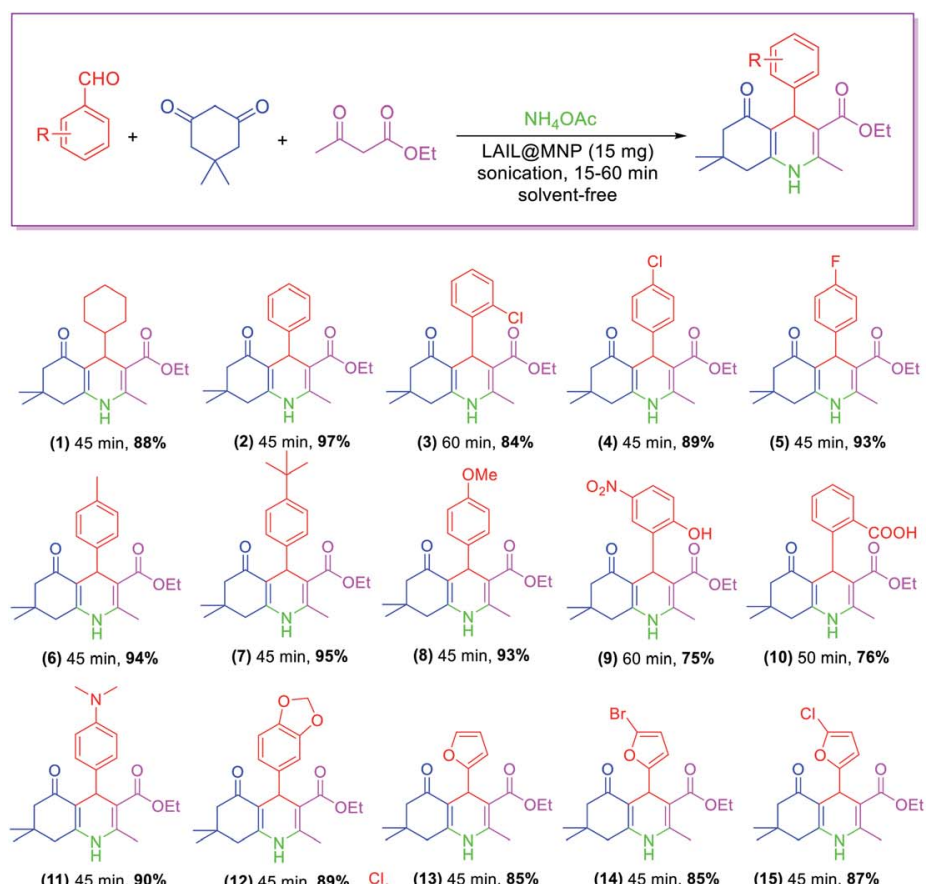

(11) $45 \mathrm{~min}, 90 \%$

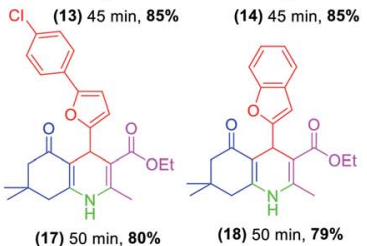
${ }^{a}$ Aldehyde $(1 \mathrm{mmol})$, ethyl acetoacetate $(1.0 \mathrm{mmol})$, dimedone $(1 \mathrm{mmol})$, and ammonium acetate $(2.0 \mathrm{mmol})$ in the presence of LAIL@MNP (15 mg)
under solvent-free sonication. Yields are isolated yield.

enhanced the electrophilicity of carbonyl carbon, providing rise to a better nucleophilic attack of dimedone to benzaldehyde to produce an intermediate (A). In the second step, $\beta$-ketoester (ethyl acetoacetate) is activated by acid catalysis with the release of ammonia from ammonium acetate $\left(\mathrm{NH}_{4} \mathrm{OAc}\right)$ to produce enamine (B) along with $\mathrm{CH}_{3} \mathrm{COOH}$ as a by-product. Then, the Michael additive reaction occurs between $(\mathbf{A})$ and (B), followed by the cyclization creating intermediate (C) and (D). Finally, the deprotonation of (D) provides the Hantzsch 1,4dihydropyridines.

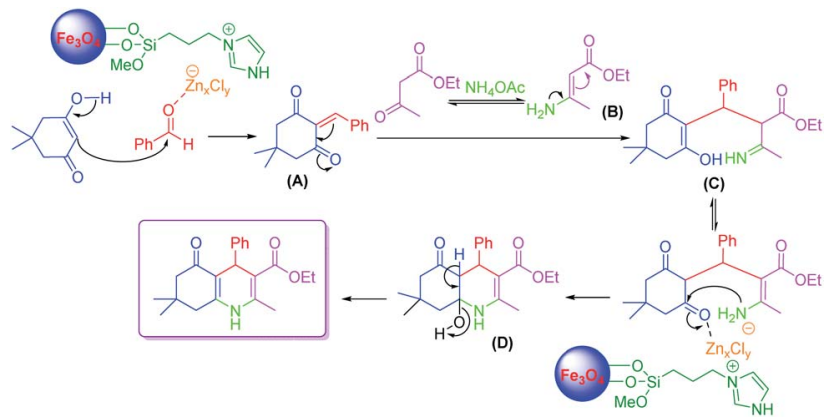

Scheme 3 Proposed mechanism for one-pot four-component synthesis of polyhydroquinolines.

\section{Synthesis of propargylamines}

The catalytic activity of LAIL@MNP was demonstrated through a one-pot multicomponent reaction of phenylacetylene, piperidine, and aldehydes under solvent-free sonication. The effect of various parameters including time, temperature, amount of catalyst, and different solvents was investigated. As can be seen from Table $\mathrm{S} 3, \uparrow$ the reaction of phenylacetylene $(1.5 \mathrm{mmol})$, piperidine $(1.2 \mathrm{mmol})$ and benzaldehyde $(1.0 \mathrm{mmol})$ was conducted at $30^{\circ} \mathrm{C}$ or $80^{\circ} \mathrm{C}$ under sonication. Interestingly, a yield of propargylamine was obtained at $80{ }^{\circ} \mathrm{C}$ for $45 \mathrm{~min}$ in the presence of LAIL@MNP. The excellent yield of (1,3diphenylprop-2-yn-1-yl)piperidine was achieved at an optimized molar ratio $1: 1.5: 1.2$ of benzaldehyde, phenylacetylene, and piperidine (entry 19). The effect of catalytic loading and solvent was also examined (entries 24-27). The results showed that the use of $10 \mathrm{mg}$ of LAIL@NMP afforded the highest yield of the product under solvent-free sonication (Table S4 $\dagger$ ). The current method was compared with other reports (Table 3), and LAIL@MNP catalyst demonstrated good catalytic performance in the preparation of propargylamines.

The scope of the substrate was explored with some aromatic aldehydes. Under the optimal conditions, the reaction proceeded smoothly to produce the corresponding propargylamines in good 
Table 3 Comparison methods for the preparation of propargylamines

\begin{tabular}{|c|c|c|c|c|}
\hline Entry & Catalytic system & Temp. $\left({ }^{\circ} \mathrm{C}\right)$ & Time (h) & Yield (\%) \\
\hline 1 & Nano CuO/toluene (10 mol\%) & 90 & 5 & 84 (ref. 73 ) \\
\hline 2 & $\mathrm{Cu} \mathrm{NPs} / \mathrm{TiO}_{2}(0.5 \% \mathrm{~mol})$ & 70 & 7 & 90 (ref. 74) \\
\hline 4 & Cu@MOF-5-C/toluene (20 mg) & 110 & 6 & 96 (ref. 76) \\
\hline 5 & $\mathrm{Cu} / \mathrm{Al} /$ toluene $(0.12 \mathrm{mmol})$ & 100 & 22 & 94 (ref. 77 ) \\
\hline 6 & Present method: LAIL@MNP (10 mg), solvent-free sonication & 80 & 0.75 & 85 \\
\hline
\end{tabular}

to excellent yields. The reaction was carried out with aryl aldehydes bearing an electron-donating or electron-withdrawing group. $p$-Methylbenzaldehyde was proceeded smoothly under optimized conditions. However, $p$-tertbutylbenzaldehyde reacted slowly and gave the desired product in moderate yield for $60 \mathrm{~min}$. The aldehydes with halo or hydroxyl substituents in the para position were also reactive with prolonged reaction time to 60$70 \mathrm{~min}$. The heterocyclic aldehyde, such as furfural and pyridine4-carbaldehyde, afforded the desired products in acceptable yields (Table 4).

A proposed mechanism for the preparation of propargylamine was demonstrated in Scheme 4. The zinc species of LAIL@MNP catalyst coordinated with oxygen on the carbonyl group of benzaldehyde, which enhanced the electrophilicity of carbonyl carbon, providing rise to a better nucleophilic attack of piperidine to benzaldehyde to produce intermediate products (E). This intermediate product was dehydrated to form benzilidenpiperidinium ion (F). Next, phenylacetylene reacted with benzilidenpiperidinium ion (F) to form the desired product.

The recyclability of LAIL@MNP was tested in the preparation of propargylamine under optimal reaction conditions (Fig. 1).

Table 4 LAIL@NMP-catalyzed for the synthesis of propargylamines ${ }^{a}$

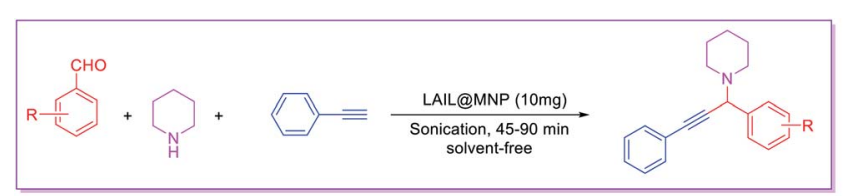

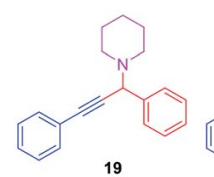

$45 \mathrm{~min})$ Conversion $95 \%$

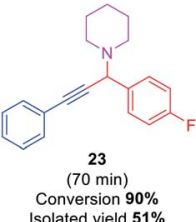
Isolated yield $\mathbf{5 1 \%}$ Isolated yield $85 \%$

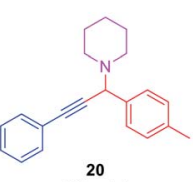

$(45 \mathrm{~min})$ Conversion $95 \%$ Isolated yield $\mathbf{6 5 \%}$

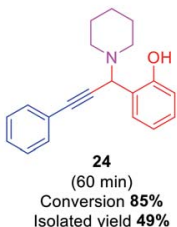
Isolated yield $\mathbf{4 9} \%$

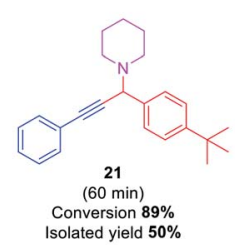

Isolated yield $\mathbf{5 0 \%}$

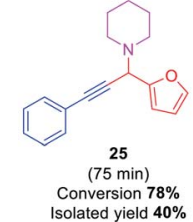

Conversion $\mathbf{7 8 \%}$
Isolated yield $\mathbf{4 0 \%}$
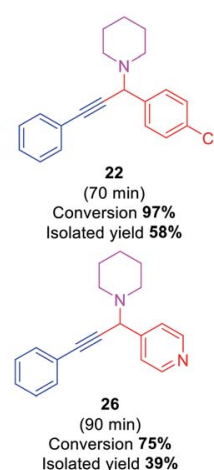

${ }^{a}$ Reaction conditions: phenylacetylene $(1.5 \mathrm{mmol})$, piperidine $(1.2$ $\mathrm{mmol})$, and aldehyde $(1.0 \mathrm{mmol})$ under solvent-free ultrasound irradiation. The conversion was determined by GC-MS based on aldehyde. Isolated yield was calculated based on the obtained amount after flash column chromatography.

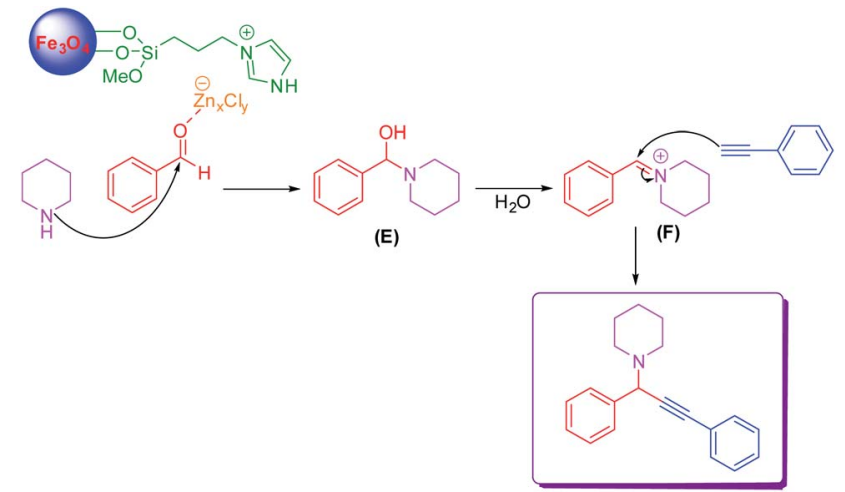

Scheme 4 A plausible mechanism for the synthesis of propargylamines.

After completion, the reaction mixture was diluted with ethyl acetate $(30 \mathrm{~mL})$ and the LAIL@MNP was removed by an external magnet. The LAIL@MNP was then washed with ethyl acetate (3 $\times 3 \mathrm{~mL})$, ethanol $(3 \times 3 \mathrm{~mL})$, and dried in vacuo. The activity of the recovered catalyst was assessed five consecutive recycling tests. The FT-IR spectrum of recovered LAIL@MNP suggested no significant change in functionality (please see ESI, Fig. S7†).

\section{Experimental}

\section{Synthesis of LAIL@MNP}

LAIL@MNP was prepared according to a procedure reported previously in the literature. ${ }^{78,79}$ The LAIL@MNP has been

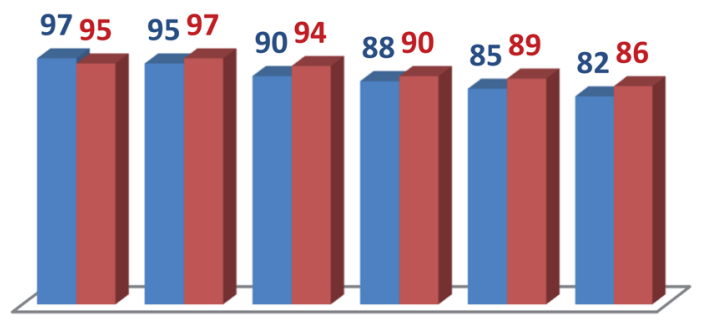

Run 0 Run 1 Run 2 Run 3 Run 4 Run 5

- Polyhydroquinoline Propargylamine

Fig. 1 Recycling of LAIL@MNP for the synthesis of polyhydroquinolines. 
evaluated by FT-IR, Raman, TGA, SEM, TEM, ICP-OES, and EDS (please see in $\mathrm{ESI}^{\dagger}$ ).

\section{Synthesis of polyhydroquinolines}

In a typical experiment, a reaction mixture of aldehyde (1.0 mmol, $0.106 \mathrm{~g})$, ethyl acetoacetate $(1.0 \mathrm{mmol}, 0.130 \mathrm{~g})$, dimedone (1.0 mmol, $0.140 \mathrm{~g})$, ammonium acetate $(2.0 \mathrm{mmol}$, $0.144 \mathrm{~g}$ ), and LAIL@MNP (15 mg) was sonicated at $80^{\circ} \mathrm{C}$. After completion, $10 \mathrm{~mL}$ ethyl acetate was added and the LAIL@MNP was separated from an organic phase by an external magnet. The ethyl acetate layer was extracted wit water $(3 \times 15 \mathrm{~mL})$, dried with anhydrous $\mathrm{Na}_{2} \mathrm{SO}_{4}$ and evaporated under vacuum. The residue was recrystallized from hot ethanol to give polyhydroquinoline. Synthesized products were confirmed by ${ }^{1} \mathrm{H},{ }^{13} \mathrm{C}$ NMR, and MS.

\section{Synthesis of propargylamines}

In a typical experiment, a reaction mixture of aldehyde $(1.0 \mathrm{mmol}$, $0.106 \mathrm{~g})$, phenylacetylene (1.5 mmol, $0.153 \mathrm{~g})$, piperidine (1.2 mmol, $0.102 \mathrm{~g}$ ), and LAIL@MNP (10 mg) was sonicated at $80{ }^{\circ} \mathrm{C}$. After completion, $10 \mathrm{~mL}$ ethyl acetate was added, and the LAIL@MNP was separated from an organic phase by an external magnet. The organic solution was then dried with anhydrous $\mathrm{Na}_{2} \mathrm{SO}_{4}$. The solvent was removed under vacuum, and the crude product was purified through column chromatography using $n$ hexane/ethyl acetate (9/1) to provide pure propargylamine. Synthesized products were confirmed by ${ }^{1} \mathrm{H},{ }^{13} \mathrm{C}$ NMR, and MS.

\section{Conclusions}

In summary, we have developed a recyclable and efficient LAIL@MNP catalyst for the synthesis of polyhydroquinolines and propargylamines. The present method demonstrated a facile and green approach toward polyhydroquinolines and propargylamines under ultrasound irradiation. The LAIL@MNP can be quickly recovered and reused without a considerable decline in catalytic activity.

\section{Conflicts of interest}

There are no conflicts of interests to declare.

\section{Acknowledgements}

Hai Truong Nguyen acknowledges the Domestic Master/PhD Scholarship Programme of Vingroup Innovation Foundation (VINIF.2019.TS.20) for polyhydroquilonine derivatives synthesis and characterization. Phuong Hoang Tran acknowledges the Vietnam National University - Ho Chi Minh City (VNU-HCM) through Project No. 562-2020-18-01 for catalytic investigation for propargylamine synthesis and LAIL@MNP preparation characterization.

\section{Notes and references}

1 N. Mizuno and M. Misono, Chem. Rev., 1998, 98, 199-218.
2 Y.-M. Wang, V. Ulrich, G. F. Donnelly, F. Lorenzini, A. C. Marr and P. C. Marr, ACS Sustainable Chem. Eng., 2015, 3, 792-796.

3 V. Polshettiwar, R. Luque, A. Fihri, H. Zhu, M. Bouhrara and J. M. Basset, Chem. Rev., 2011, 111, 3036-3075.

4 Y. K. Tailor, S. Khandelwal, R. Gopal, E. Rushell, A. Prajapati and M. Kumar, ChemistrySelect, 2017, 2, 11055-11061.

5 A. R. Kiasat and J. Davarpanah, J. Mol. Catal. A: Chem., 2013, 373, 46-54.

6 J. Safari and Z. Zarnegar, RSC Adv., 2015, 5, 17738-17745.

7 X.-N. Zhao, G.-F. Hu, M. Tang, T.-T. Shi, X.-L. Guo, T.-T. Li and Z.-H. Zhang, RSC Adv., 2014, 4, 51089-51097.

8 A. Tadjarodi, R. Khodikar and H. Ghafuri, RSC Adv., 2016, 6, 63480-63487.

9 S. Swami, A. Agarwala and R. Shrivastava, New J. Chem., 2016, 40, 9788-9794.

10 Y. Zhang, Y. Zhao and C. Xia, J. Mol. Catal. A: Chem., 2009, 306, 107-112.

11 X. Zheng, S. Luo, L. Zhang and J.-P. Cheng, Green Chem., 2009, 11, 455-458.

12 I. Cano, C. Martin, J. A. Fernandes, R. W. Lodge, J. Dupont, F. A. Casado-Carmona, R. Lucena, S. Cardenas, V. Sans and I. de Pedro, Appl. Catal., B, 2020, 260, 118110.

13 A. Alizadeh, M. Fakhari, M. M. Khodeai, G. Abdi and J. Amirian, RSC Adv., 2017, 7, 34972-34983.

14 B. Atashkar, M. A. Zolfigol and S. Mallakpour, Mol. Catal., 2018, 452, 192-246.

15 L. R. Morgan, B. S. Jursic, C. L. Hooper, D. M. Neumann, K. Thangaraj and B. LeBlanc, Bioorg. Med. Chem. Lett., 2002, 12, 3407-3411.

16 P. Beagley, M. A. L. Blackie, K. Chibale, C. Clarkson, R. Meijboom, J. R. Moss, P. J. Smith and H. Su, Dalton Trans., 2003, 3046-3051.

17 P. N. Kalaria, S. P. Satasia and D. K. Raval, Eur. J. Med. Chem., 2014, 78, 207-216.

18 N. Fokialakis, P. Magiatis, I. Chinou, S. Mitaku and F. Tillequin, Chem. Pharm. Bull., 2002, 50, 413-414.

19 J.-C. Liang, J.-L. Yeh, C.-S. Wang, S.-F. Liou, C.-H. Tsai and I.-J. Chen, Bioorg. Med. Chem., 2002, 10, 719-730.

20 A. Ryckebusch, R. Deprez-Poulain, L. Maes, M.-A. DebreuFontaine, E. Mouray, P. Grellier and C. Sergheraert, J. Med. Chem., 2003, 46, 542-557.

21 F. Bossert, H. Meyer and E. Wehinger, Angew. Chem., Int. Ed., 1981, 20, 762-769.

22 A. Kumar, S. Sharma, V. D. Tripathi, R. A. Maurya, S. P. Srivastava, G. Bhatia, A. K. Tamrakar and A. K. Srivastava, Bioorg. Med. Chem., 2010, 18, 4138-4148.

23 J. L. Donelson, R. A. Gibbs and S. K. De, J. Mol. Catal. A: Chem., 2006, 256, 309-311.

24 M. Hong, C. Cai and W.-B. Yi, J. Fluorine Chem., 2010, 131, 111-114.

25 R. Surasani, D. Kalita, A. V. D. Rao, K. Yarbagi and K. B. Chandrasekhar, J. Fluorine Chem., 2012, 135, 91-96.

26 M. Nasr-Esfahani, B. Karami and M. Behzadi, J. Heterocycl. Chem., 2009, 46, 931-935.

27 A. Dondoni, A. Massi and M. Aldhoun, J. Org. Chem., 2007, 72, 7677-7687. 
28 T. A. Moss and T. Nowak, Tetrahedron Lett., 2012, 53, 30563060 .

29 L.-M. Wang, J. Sheng, L. Zhang, J.-W. Han, Z.-Y. Fan, H. Tian and C.-T. Qian, Tetrahedron, 2005, 61, 1539-1543.

30 S. S. Katkar, P. H. Mohite, L. S. Gadekar, B. R. Arbad and M. K. Lande, Green Chem. Lett. Rev., 2010, 3, 287-292.

31 M. M. Heravi, M. Saeedi, N. Karimi, M. Zakeri, Y. S. Beheshtiha and A. Davoodnia, Synth. Commun., 2010, 40, 523-529.

32 M. Hong, C. Cai and W.-B. Yi, J. Fluorine Chem., 2010, 131, 111-114.

33 M. Tajbakhsh, H. Alinezhad, M. Norouzi, S. Baghery and M. Akbari, J. Mol. Liq., 2013, 177, 44-48.

34 S. B. Sapkal, K. F. Shelke, B. B. Shingate and M. S. Shingare, Tetrahedron Lett., 2009, 50, 1754-1756.

35 M. Saha and A. K. Pal, Tetrahedron Lett., 2011, 52, 4872-4877. 36 M. Abdollahi-Alibeik and A. Rezaeipoor-Anari, J. Magn. Magn. Mater., 2016, 398, 205-214.

37 S. T. Fardood, A. Ramazani and S. Moradi, J. Sol-Gel Sci. Technol., 2017, 82, 432-439.

38 M. Nasr-Esfahani, S. J. Hoseini, M. Montazerozohori, R. Mehrabi and H. Nasrabadi, J. Mol. Catal. Chem., 2014, 382, 99-105.

39 S. Taghavi Fardood, A. Ramazani, Z. Golfar and S. W. Joo, Appl. Organomet. Chem., 2017, 31, e3823.

40 L. Saikia, D. Dutta and D. K. Dutta, Catal. Commun., 2012, 19, 1-4.

41 A. Maleki, A. R. Akbarzade and A. R. Bhat, J. Nanostruct. Chem., 2017, 7, 309-316.

42 A. Ghorbani-Choghamarani, B. Tahmasbi, P. Moradi and N. Havasi, Appl. Organomet. Chem., 2016, 30, 619-625.

43 R. Surasani, D. Kalita, A. V. D. Rao, K. Yarbagi and K. B. Chandrasekhar, J. Fluorine Chem., 2012, 135, 91-96.

44 J. S. Yoo, T. J. Laughlin, J. J. Krob and R. S. Mohan, Tetrahedron Lett., 2015, 56, 4060-4062.

45 S. Ko and C.-F. Yao, Tetrahedron, 2006, 62, 7293-7299.

46 S. Mondal, B. C. Patra and A. Bhaumik, ChemCatChem, 2017, 9, 1469-1475.

47 C. G. Evans and J. E. Gestwicki, Org. Lett., 2009, 11, 29572959.

48 Z. Zarnegar, J. Safari and Z. M. Kafroudi, New J. Chem., 2015, 39, 1445-1451.

49 O. Goli-Jolodar, F. Shirini and M. Seddighi, $R S C$ Adv., 2016, 6, 26026-26037.

50 T. K. Saha and R. Das, ChemistrySelect, 2018, 3, 147-169.

51 F. Xiao, Y. Chen, Y. Liu and J. Wang, Tetrahedron, 2008, 64, 2755-2761.

52 N. Shachat and J. J. Bagnell, J. Org. Chem., 1963, 28, 991-995. 53 C. G. Overberger and J.-P. Anselme, J. Org. Chem., 1963, 28, 592-593.

54 B. Yan and Y. Liu, Org. Lett., 2007, 9, 4323-4326.

55 E.-S. Lee, H.-S. Yeom, J.-H. Hwang and S. Shin, Eur. J. Org. Chem., 2007, 2007, 3503-3507.
56 C. Jiang, M. Xu, S. Wang, H. Wang and Z.-J. Yao, J. Org. Chem., 2010, 75, 4323-4325.

57 D. Shibata, E. Okada, J. Molette and M. Médebielle, Tetrahedron Lett., 2008, 49, 7161-7164.

58 Y. Yamamoto, H. Hayashi, T. Saigoku and H. Nishiyama, J. Am. Chem. Soc., 2005, 127, 10804-10805.

59 D. F. Harvey and D. M. Sigano, J. Org. Chem., 1996, 61, 22682272.

60 F. J. Fañanás, T. Arto, A. Mendoza and F. Rodríguez, Org. Lett., 2011, 13, 4184-4187.

61 T. S. Symeonidis, M. G. Kallitsakis and K. E. Litinas, Tetrahedron Lett., 2011, 52, 5452-5455.

62 M. Naoi, W. Maruyama, Y. Akao, H. Yi and Y. Yamaoka, in Oxidative Stress and Neuroprotection, ed. $\mathrm{H}$. Parvez and $\mathrm{P}$. Riederer, Springer Vienna, Vienna, 2006, pp. 67-77, DOI: 10.1007/978-3-211-33328-0_8.

$63 \mathrm{~J}$. Leegwater-Kim and E. Bortan, Clin. Interventions Aging, 2010, 5, 149-156.

64 V. A. Peshkov, O. P. Pereshivko, A. A. Nechaev, A. A. Peshkov and E. V. Van der Eycken, Chem. Soc. Rev., 2018, 47, 38613898.

65 H. T. Nguyen, N. P. T. Le, D. K. N. Chau and P. H. Tran, RSC Adv., 2018, 8, 35681-35688.

66 M. M. Hooper and B. DeBoef, J. Chem. Educ., 2009, 86, 1077. 67 M. Shiri, Chem. Rev., 2012, 112, 3508-3549.

68 S. R. Cherkupally and R. Mekala, Chem. Pharm. Bull., 2008, 56, 1002-1004.

69 L. S. K. Gadekar, S. Santosh, S. R. Mane, B. R. Arbad and M. K. Lande, Bull. Korean Chem. Soc., 2009, 30, 2532-2534.

70 A. Mobinikhaledi, N. Foroughifar, M. A. B. Fard, H. Moghanian, S. Ebrahimi and M. Kalhor, Synth. Commun., 2009, 39, 1166-1174.

71 R. T. Behrooz Maleki, M. Kermanian and S. S. Ashrafi, J. Mex. Chem. Soc., 2013, 57, 290-297.

72 H. Khabazzadeh, E. T. Kermani, D. Afzali, A. Amiri and A. Jalaladini, Arabian J. Chem., 2012, 5, 167-172.

73 M. Lakshmi Kantam, S. Laha, J. Yadav and S. Bhargava, Tetrahedron Lett., 2008, 49, 3083-3086.

74 M. J. Albaladejo, F. Alonso, Y. Moglie and M. Yus, Eur. J. Org. Chem., 2012, 2012, 3093-3104.

75 H.-B. Chen, Y. Zhao and Y. Liao, RSC Adv., 2015, 5, 3773737741.

76 S. Cheng, N. Shang, C. Feng, S. Gao, C. Wang and Z. Wang, Catal. Commun., 2017, 89, 91-95.

77 J. Dulle, K. Thirunavukkarasu, M. C. Mittelmeijer-Hazeleger, D. V. Andreeva, N. R. Shiju and G. Rothenberg, Green Chem., 2013, 15, 1238-1243.

78 S. Nazari, S. Saadat, P. K. Fard, M. Gorjizadeh, E. R. Nezhad and M. Afshari, Monatsh. Chem., 2013, 144, 1877-1882.

79 H. T. Nguyen, N.-P. Thi Le, D.-K. Nguyen Chau and P. H. Tran, RSC Adv., 2018, 8, 35681-35688. 